\title{
Manifestação patológica precoce em bloco de fundação
}

\author{
SERGIO BOTASSI DOS SANTOS - M.Sc., DR. * \\ Consultor da SBS Engenharia, Coordenador de Pós-Graduação do IP0G e Professor PUC-G0
}

\author{
FLÁVIO DE LIMA VIEIRA - M.Sc. \\ Furnas Centrais Elétricas, Especialista em Concreto
}

\begin{abstract}
RESUMO
A NORMA BRASILEIRA DE DESEMPENHO PARA EDIFICAÇÕES HABITACIONAIS (ABNT NBR15.575-1), ESPECIFICA QUE A VIDA ÚTIL ESTRUTURAL MÍNIMA DE UMA EDIFICAÇÃO SEJA DE 50 ANOS, ESPERANDO ASSIM QUE AS MANIFESTAÇÕES PATOLÓGlCAS MAIS RELEVANTES OCORRAM A LONGO PRAZO. CONTUDO, ESSA EXPECTATIVA NEM SEMPRE É RESPEITADA, SURGINDO PROBLEMAS ESTRUTURAIS DE FORMA PRECOCE AINDA NA FASE CONSTRUTIVA, ALGUMAS DELAS ORIUNDAS DO NÃO ATENDIMENTO AOS REQUISITOS DE PROJETO. ESTE TRABALHO APRESENTA UM ESTUDO DE CASO NO QUAL FOI OBSERVADO UM QUADRO DE FISSURAÇÃO GENERALIZADO EM UM BLOCO DE ENCABEÇAMENTO DE ESTACAS DE FUNDAÇÃO DURANTE A FASE DE CONSTRUÇÃO. FOI REALIZADA UMA ANÁLISE MINUCIOSA PARA AVALIAR O DIAGNÓSTICO DO
\end{abstract}

FENÔMENO PATOLÓGICO E ASSIM PROPOR MEDIDAS DE MITIGAÇÃO PROPORCIONAL AO DANO. CONSTATOU-SE COMO UMA DAS PRINCIPAIS CAUSAS O EFEITO TÉRMICO DO CONCRETO NAS PRIMEIRAS IDADES, MESMO O BLOCO APRESENTANDO VOLUME DE CONCRETO NÃO MUITO EXPRESSIVO. POSTERIORMENTE FORAM APRESENTADAS MEDIDAS DE RECUPERAÇÃO ESTRUTURAL COM O AVAL DO PROJETISTA DA FUNDAÇÃO PARA QUE A ESTRUTURA VOLTASSE A RESPEITAR AS CONDICIONANTES DE PROJETO. TAL ESTUDO DE CASO REAL SERVE COMO UM ALERTA PARA SE TOMAR CUIDADOS ESPECIAIS DE CONCRETAGEM AINDA NA FASE DE PLANEJAMENTO DA OBRA, POIS A RECUPERAÇÃO ALÉM DE MAIS ONEROSA TENDE A GERAR UMA SÉRIE DE TRANSTORNOS QUE PODERIAM SER EVITADOS A BAIXO CUSTO.

Palavras-chave: patologia, recuperação, problema térmico, bloco de fundação.

\section{INTRODUÇÃOO}

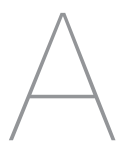

ABNT NBR 15.575 (ABNT, 2013) no escopo das suas seis partes constituintes estabelece parâmetros mínimos de desempenho para que a edificação consiga atingir a capacidade de apresentar durabilidade com segurança e conforto ao longo de sua vida útil. Contudo, as práticas de construção civil ainda apresentam recorrentes manifestações patológicas que precisam ser combatidas em sua origem. Esses vícios decorrentes de uma histórica cultura de não se dispor a devida atenção à definições de planejamento e ordem executiva, refletem em prejuízos à sociedade como um todo.

O que chama a atenção dessas manifestações patológicas é a forma precoce com que muitas delas ocorrem, incidindo muitas vezes ainda na fase de construção da edificação. Tal fato pode estar associado a inúmeros fatores de ordem gerencial, técnica e administrativa na execução da obra, mas que não eximem de responsabilidade todos envolvidos no planejamento da obra e estudo do processo construtivo. Cuidado ainda maior deve ser tomado quando envolve a execução de elementos estruturais, como no caso de fundações que será explanado neste artigo, em função dos riscos de colapso ou perda prematura de durabilidade da edificação.

A finalidade deste artigo é de apontar as prováveis causas patológicas de grandes fissuras ocorridas em blocos de coroamento de estacas de um edifício, cuja origem se deu poucos meses depois de sua execução, ainda na fase de construção da obra.
Além disso, são apresentadas as soluções implantadas de recuperação do bloco, incluindo a execução.

\section{DESCRIÇÃO DO BLOCO}

Este estudo de caso patológico ocorreu em alguns blocos de coroamento de estacas de fundação de um edifício residencial ainda na fase construtiva na cidade de Goiânia-GO. Para fins de compilação das informações neste artigo, será dado enfoque em apenas um dos blocos, cujo quadro patológico se demonstrou mais grave e generalizado.

\section{I Dimensõ€s $€$ armação}

O bloco cujas manifestações patológicas se demonstraram mais severas apresenta as informações básicas resumidas na Tabela 1. Esse bloco faz

*sergio_botassi@yahoo.com.br 
a ligação da fundação com a superestrutura, apresentando seis estacas escavadas, cuja carga de projeto do pilar sobre o bloco é de $590 \mathrm{tf}$.

As maiores taxas de armadura posicionam-se na parte inferior do bloco na sua maior dimensão $(3,4 \mathrm{~m})$ com bitolas de $25 \mathrm{~mm}$ a cada $14 \mathrm{~cm}$, demonstrando a robustez estrutural. A espessura do bloco de $1,30 \mathrm{~m}$ aliado ao expressivo $f_{c k}$ pode ser um sinal de que cuidados térmicos na concretagem seriam necessários, como recomenda Botassi et alli. (2011) e Botassi (2019).

\subsection{Tecnologia do concreto}

Foram obtidos resultados de controle tecnológico do concreto pela construtora, a fim de averiguar o atendimento aos requisitos de projeto. Os ensaios de resistência à compressão foram realizados para duas idades de controle (7 e 28 dias), cujos valores encontram-se resumidos na Tabela 2.

Ressalta-se no controle da resistência à compressão de que o resultado aos 7 dias já superava em $10 \%$ o $f_{c k}$ de projeto e aos 28 dias em $27 \%$. Este fato sob o aspecto de segurança estrutural demonstra-se obviamente aceitável,

\begin{tabular}{|c|c|}
\hline \multicolumn{2}{|c|}{$\begin{array}{l}\text { Tabela } 1 \text { - Descrição básica de } \\
\text { projeto do bloco de coroamento } \\
\text { de fundação }\end{array}$} \\
\hline Característica & Valor \\
\hline $\begin{array}{l}\text { Dimensões } \\
\text { nominais }\end{array}$ & $\begin{array}{c}3,40 \times 2,10 \times 1,30 \\
(\mathrm{~m})\end{array}$ \\
\hline Volume nominal & $9,3 \mathrm{~m}^{3}$ \\
\hline$f_{c k}$ & $45 \mathrm{MPa}$ aos 28 dias \\
\hline Taxa de aço & $\begin{array}{c}76,6 \mathrm{~kg} / \mathrm{m}^{3} \\
\text { concreto }\end{array}$ \\
\hline Cobrimento & $5 \mathrm{~cm}$ \\
\hline
\end{tabular}

mas por outro lado é resultado de um provável excesso no consumo de ligantes na dosagem para se atingir o $f_{c k}$, 0 que induz a uma variação dimensional do concreto mais relevante (térmica e hidráulica), muito embora não se tenha tido o valor de a/c da carta-traço para afirmar categoricamente essa situação.

\section{INVESTIGAÇÃO}

A análise do bloco de coroamento de estacas visou diagnosticar os principais danos estruturais neste elemento de fundação, incluindo a magnitude de seus efeitos, e verificar por meio de simulações numéricas as potenciais causas associadas, com o intuito final de se dimensionar a recuperação estrutural e restabelecer o desempenho do bloco.

\section{I Levantamento dos danos}

Um dos blocos mais danificados apresentou fissuração generalizada com propagação bem definida (Figura 1a), tendendo a se direcionar do centro do bloco, onde se encontra o pilar, para os vértices, como observado na Figura 1b. Após a escavação lateral do bloco observou-se a propagação das fissuras, apresentando indícios de que o grau de fissuração interferiu na capacidade portante deste elemento estrutural.

As fissuras apresentavam espessura variável, mas a grande parte delas possuía ordem de grandeza entre $2 \mathrm{~mm}$ e $4 \mathrm{~mm}$ (Figura 2a), comprovando que, além de haver perda de capacidade portante, a estrutura estava com a sua durabilidade comprometida. As fissuras nas faces laterais dos blocos diminuíam de espessura com a proximidade da base vinculada às estacas de fundação (Figura 2b). Verificou-se ainda por meio
Tabela 2 - Informações básicas

da tecnologia do concreto do bloco

\begin{tabular}{|c|c|}
\hline Caracteristica & Valor \\
\hline $\begin{array}{c}\text { Horário da } \\
\text { concretagem }\end{array}$ & $12 \mathrm{~h} 30$ \\
\hline Abatimento & $140 \mathrm{~mm}$ \\
\hline Resistência à & aos 7 dias \\
\hline compressão médio & $57,3 \mathrm{MPa}$ \\
& aos 28 dias \\
\hline
\end{tabular}

de monitoramento, utilizando marcas de gesso, que as fissuras ao longo de algumas semanas, não estavam aumentando de forma expressiva em sua espessura e extensão, concluindo-se por sua estabilidade (fissuras passivas).

Foram realizados alguns ensaios não destrutivos para avaliar a integridade estrutural do concreto (utilizando o esclerômetro) e presença de armação por meio de equipamento com emissão de campo eletromagnético (pacômetro), conforme destacados na Figura 3.

Os ensaios com esclerômetro foram prejudicados, pois as superfícies não apresentaram planicidade suficiente para se garantir uma predição razoável em termos absolutos. Contudo, foi possível observar pelos resultados relativos que a rigidez do bloco variou na sua superfície o que poderia ser um indício de falta de homogeneidade do concreto por segregação ou exsudação durante a concretagem. A partir do pacômetro não foi possível precisar a taxa de armadura, até mesmo porque o aparelho possui a capacidade de detecção de até $12 \mathrm{~cm}$ de profundidade dentro da estrutura, embora tenha se percebido um certo padrão de espaçamento da armadura 


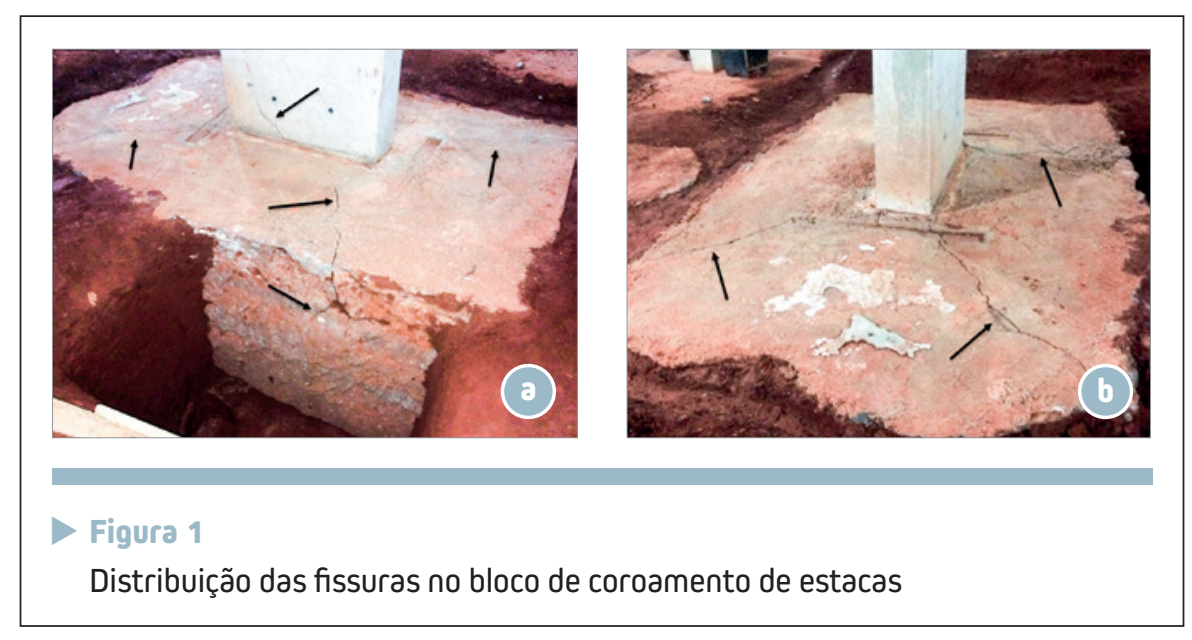

ao longo do maciço. Por outro lado, foi constatada baixa presença de ferragem próxima a superfície, possivelmente associado ao fato das dimensões reais do bloco serem superiores às definidas em projeto, induzindo a um posicionamento mais profundo das barras de aço e, consequentemente, maior cobrimento (segundo o projeto era de $5 \mathrm{~cm}$ ).

\subsection{Estudo das causas}

Um dos aspectos mais relevantes observados foi o momento em que as fissuras foram observadas, com apenas 9 meses após a concretagem do bloco, durante o processo de construção do edifício, quando havia menos da metade do peso próprio solicitante e praticamente sem carga acidental expressiva sobre a fundação, descartando a hipótese de sobrecarga. Como também não ficou explícita a ausência de armadura e o concreto apresentou capacidade resistente acima do $f_{c k}$ de projeto, pode-se inferir que a causa patológica provavelmente não estivesse associada ao desempenho mecânico.

Foi investigado então o risco de fissuração por variação dimensional do

Para verificar se a causa do esta-

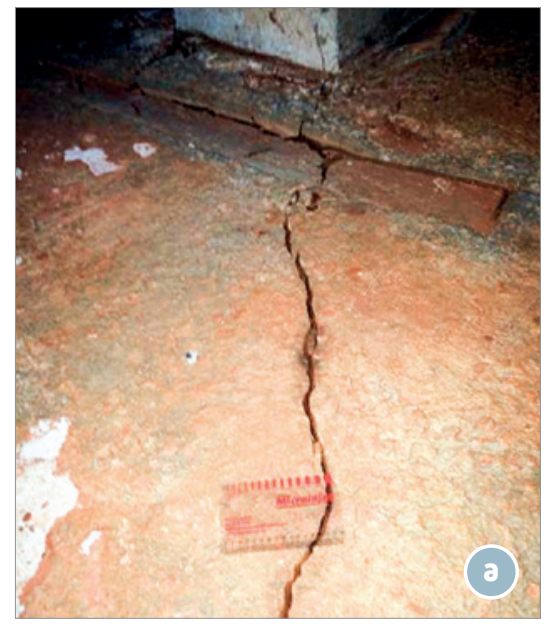

Figura 2

Verificação da espessura das fissuras do crítico de fissuração do bloco estaria vinculada ao problema térmico, adotou-se, como estratégia, realizar simulações computacionais por meio de retroanálise a partir das poucas informações disponíveis a respeito do processo de concretagem. Para tanto, a primeira etapa foi estimar as propriedades do concreto e entorno para alimentar as simulações.

Um dos grandes desafios do trabaIho de recuperação do bloco foi a obtenção da carta-traço do concreto utilizado na obra. Por alegações do cliente, foi informado que a mesma não estaria disponível pelo fornecedor do concreto, pois o mesmo foi trocado e dificultou o acesso às informações. Os dados disponíveis ficaram limitados, então, ao tipo de cimento utilizado e origem litológica dos agregados.

A fim de suprir essa deficiência e permitir os devidos estudos, estimou-se o consumo de cimento CPII-F-40 de $510 \mathrm{~kg} / \mathrm{m}^{3}$, tomando como referência o nível de resistência à compressão alcançado e utilizando as curvas de predição de Botassi (2019), para

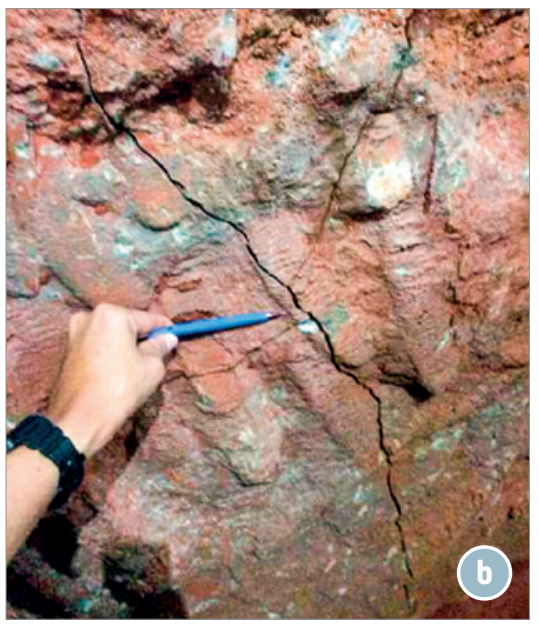




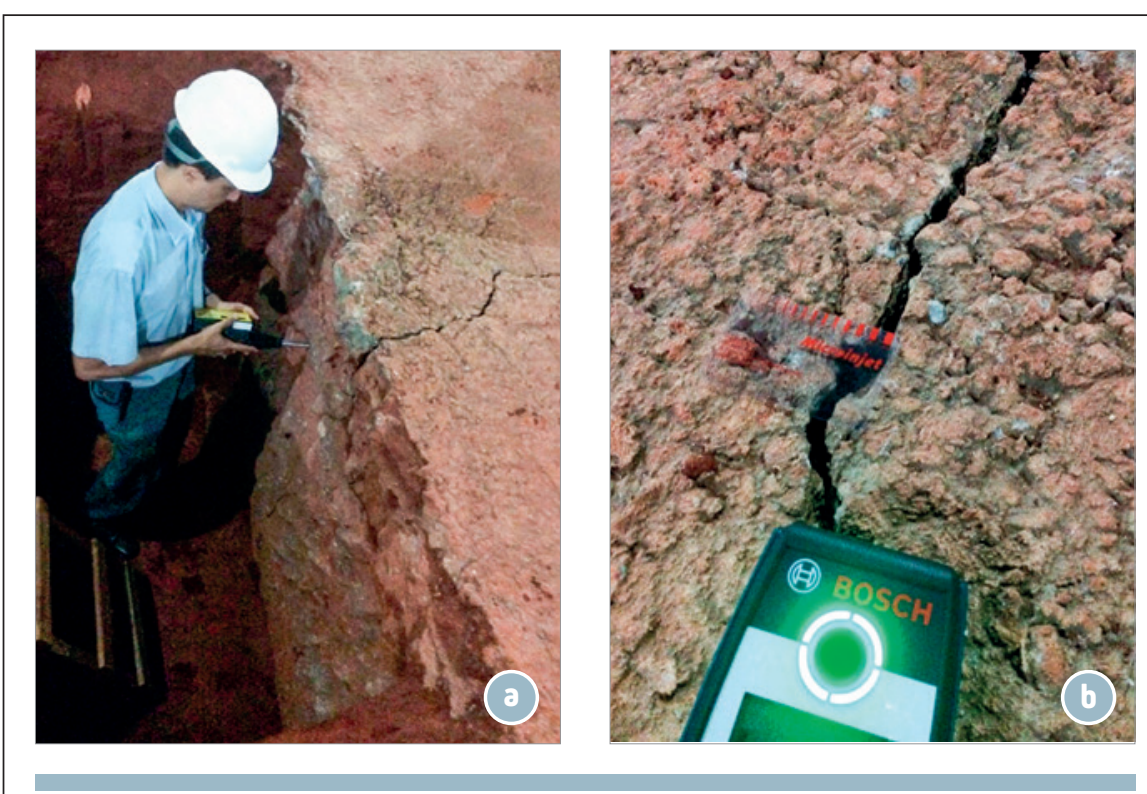

Figura 3

Ensaios não destrutivos: (a) esclerometria; (b) pacômetro indicando armação

definir as principais propriedades térmicas, resumidas na Tabela 3 e Figura 4. Para as propriedades mecânicas foi adotada como referência a resistência à compressão obtida no controle tecnológico da obra

\begin{tabular}{|c|c|c|}
\hline \multicolumn{3}{|c|}{$\begin{array}{l}\text { Tabela } 3 \text { - Estimativa das } \\
\text { propriedades do concreto }\end{array}$} \\
\hline \multicolumn{2}{|c|}{ Propriedades térmicas } & Estimativa \\
\hline \multicolumn{2}{|c|}{$\begin{array}{l}\text { Coef. de expansão térmica } \\
\qquad\left(10^{-6} /{ }^{\circ} \mathrm{C}\right)\end{array}$} & 13,92 \\
\hline \multicolumn{2}{|c|}{ Calor específico (cal/g. $\left.{ }^{\circ} \mathrm{C}\right)$} & 0,269 \\
\hline \multicolumn{2}{|c|}{$\begin{array}{l}\text { Condutividade térmica } \\
\qquad\left(\mathrm{W} / \mathrm{m} .{ }^{\circ} \mathrm{C}\right)\end{array}$} & 1,951 \\
\hline \multirow{3}{*}{$\begin{array}{l}\text { Módulo de } \\
\text { elasticidade } \\
\text { (GPa) }\end{array}$} & 3 dias & 30,63 \\
\hline & 7 dias & 34,95 \\
\hline & 28 dias & 39,60 \\
\hline \multirow{3}{*}{$\begin{array}{l}\text { Resistência } \\
\text { à tração na } \\
\text { flexão (MPa) }\end{array}$} & 3 dias & 4,13 \\
\hline & 7 dias & 4,92 \\
\hline & 28 dias & 5,82 \\
\hline \multirow{3}{*}{$\begin{array}{c}\text { Coeficiente } \\
\text { de fluência } \\
\left(10^{-6} /(\mathrm{MPa} \text {. }\right. \\
\ln (\text { dia })))\end{array}$} & 3 dias & 7,70 \\
\hline & 7 dias & 6,66 \\
\hline & 28 dias & 5,80 \\
\hline
\end{tabular}

e as equações preditivas da ABNT NBR6118 (ABNT, 2014).

As propriedades do entorno foram estimadas a partir dos resultados climáticos para os meses em que o bloco foi concretado (Tabela 4), como registrado nos dados do controle tecnológico do concreto. Estimou-se a concretagem sendo executada em uma única camada sob condições climáticas típicas da região de Goiânia-GO, onde a obra foi realizada.

\subsection{Análise termotensional}

Foi simulada a distribuição do campo de temperaturas na estrutura na condição unidirecional ao longo do tempo por meio do software Thermal Stress Analisys - One dimension (TSA-1D), conforme Botassi (2019). Foram avaliados resultados de temperatura em duas regiões do bloco: próximo à superfície $(15 \mathrm{~cm})$ e no centro, conforme apresentado no gráfico da Figura 5. A temperatura máxima atingida na estrutura foi de $64,19^{\circ} \mathrm{C}$ aos

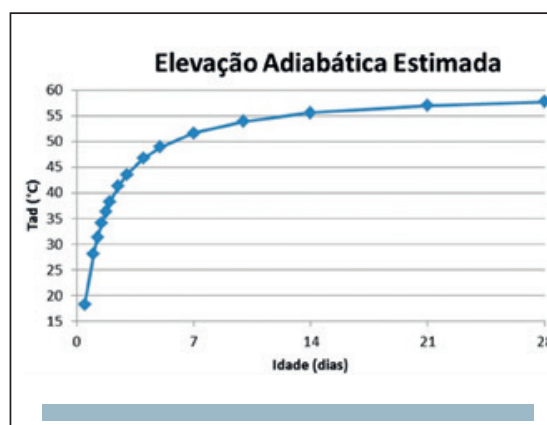

Figura 4

Elevação adiabática estimada do concreto

2,5 dias, próxima ao centro do bloco. Este valor de temperatura elevada se dissipou em poucos dias, como observado no gráfico, o que explica o pico de

Tabela 4 - Condições de contorno da simulação

\begin{tabular}{|c|c|c|}
\hline \multicolumn{3}{|c|}{ Condições ambientais adotadas } \\
\hline Modo & $\begin{array}{l}\text { Fluido de } \\
\text { contato }\end{array}$ & $\begin{array}{l}\text { Coef. de } \\
\text { Conv. } \\
\left(\mathrm{W} / \mathrm{m}^{2}{ }^{\circ} \mathrm{C}\right)\end{array}$ \\
\hline $\begin{array}{l}\text { Convecção } \\
\text { livre }\end{array}$ & $\operatorname{Ar}$ & 15 \\
\hline
\end{tabular}

\begin{tabular}{|cc|}
\multicolumn{2}{|c|}{ Temperatura ambiente* } \\
\hline $\mathrm{T}_{\text {máx }}$ & $\mathrm{T}_{\text {min }}$ \\
\hline $32^{\circ} \mathrm{C}$ & $20^{\circ} \mathrm{C}$ \\
\hline $13 \mathrm{~h} 00$ & $00 \mathrm{~h} 00$ \\
\hline
\end{tabular}

* Estimado a partir de dados do INMET

\begin{tabular}{|c|c|c|}
\hline \multicolumn{3}{|c|}{$\begin{array}{l}\text { Contato com concreto magro } \\
\text { na parte inferior }\end{array}$} \\
\hline \multicolumn{3}{|c|}{ Temperatura média constante } \\
\hline \multicolumn{3}{|c|}{$26^{\circ} \mathrm{C}$} \\
\hline \multicolumn{3}{|c|}{ Condições de lançamento do concreto } \\
\hline \multicolumn{3}{|c|}{ Temperatura de lançamento } \\
\hline \multicolumn{3}{|c|}{$31^{\circ} \mathrm{C}$} \\
\hline \multicolumn{3}{|c|}{ Hipótese - concretagem camada única } \\
\hline $\begin{array}{l}\text { Camada } \\
\text { única* }\end{array}$ & $\begin{array}{c}\text { Altura } \\
\text { (horário) }\end{array}$ & $\begin{array}{r}1,50 \mathrm{~m} \\
(12 \mathrm{~h} 00)\end{array}$ \\
\hline
\end{tabular}


temperatura não ter sido ainda maior, mas que por outro lado induziu a tensões de tração elevadas em curto prazo, antes mesmo que o concreto atingisse seu auge de resistência mecânica.

Para avaliar o efeito tensional considerou-se ainda a influência da retração total utilizando o modelo de predição da NBR 6118 (ABNT, 2014) em seu Anexo A.2.3. A estimativa de retração na idade de 270 dias foi de aproximadamente 130 micrômetros, valor este relevante que se acrescido ao efeito térmico provoca grande acúmulo de tensão, conforme simulado na Figura 6. Para o cálculo das tensões foi considerado o engastamento da sua base com as estacas a partir do modelo do ACl 207.2R (ACl, 1995) e ainda o efeito dos gradientes térmicos calculados pelo software TSA-1D.

Pelos resultados de tensão potencial provocado pelo efeito térmico em conjunto com a retração percebe-se que o risco de fissuração é relevante após três meses executada a concretagem, pois as tensões solicitantes estão próximas à capacidade resistente do concreto à tração na flexão, pressupondo essa ser o comportamento estrutural do bloco. Caso considerado a capacidade resistente por tração direta, valor este inferior à tração na flexão,

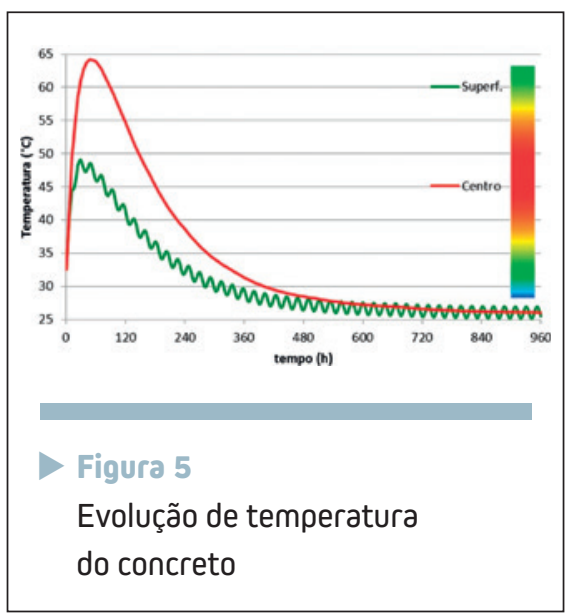

essas fissuras podem ter ocorrido ainda mais recente. Tal situação simulada estava condizente ao observado no quadro de fissuração precoce do blo$\mathrm{co}$, deduzindo ser esta uma das principais causas dos danos ocorridos.

Deve-se ainda acrescer aos efeitos tensionais provenientes das tensões térmicas o fato dos blocos após certa idade começarem a sofrer carregamento do peso próprio da estrutura, indicando, portanto, que o quadro de fissuração possa ter ocorrido já nos primeiros meses pós-concretagem entre a superfície e o centro do bloco e agravado com a evolução da obra.

\subsection{Demais fatores intervenientes}

Percebe-se pelo levantamento de dados que outros fatores podem ter contribuído para o agravamento das fissuras no bloco, com destaque para:

As dimensões foram superiores às especificadas no projeto: as dimensões reais constatadas na vistoria acresceram em mais de 30\% o volume total de concreto demandado, passando de $9,3 \mathrm{~m}^{3}$ para $12,4 \mathrm{~m}^{3}$, contrapondo-se aos limites da ABNT NBR 14.931 (ABNT, 2004);

A resistência à compressão e o abatimento do concreto utilizados nos blocos foram muito superiores aos especificados para este tipo de concreto (em torno de $27 \%$ para resistência), contribuindo para o maior consumo de cimento e volume de pasta que tende a gerar maior instabilidade volumétrica da estrutura;

> Não há registro de cuidados especiais na execução da concretagem que deveria ocorrer em situações de risco de fissuração por variação dimensional do concreto;

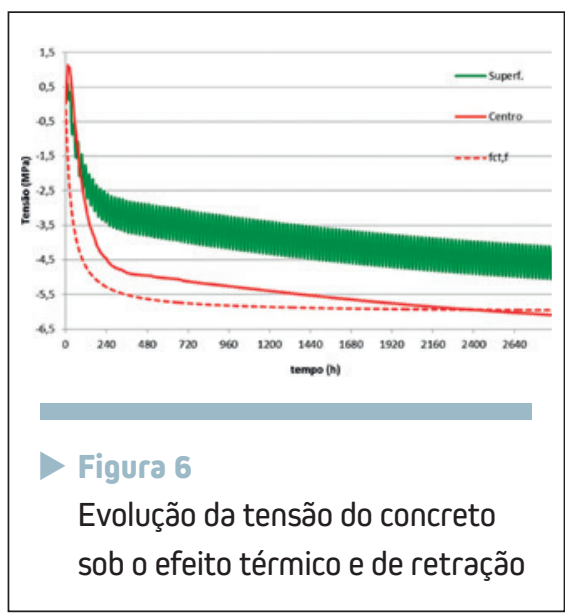

O posicionamento das armaduras situa-se em profundidade superior ao cobrimento, o que dificultou no controle das primeiras fissuras na superfície;

- Não se pode descartar o agravamento da fissuração térmica em decorrência da concentração de carga mecânica oriunda do esforço do pilar sobre o bloco (modelo biela-tirante para bloco rígido). Esse efeito pode ter se somado às fissuras já instaladas, induzindo a se propagarem pela estrutura e aumentar suas espessuras;

- Pode ter havido ainda algum risco de etringita tardia, mas acredita-se não ter sido significativo, pois a temperatura máxima não ultrapassou $65^{\circ} \mathrm{C}$ e ainda se limitou a uma pequena região no núcleo do bloco durante algumas horas.

\section{DIMENSIONAMENTO DAS SOLUÇÕES}

O dimensionamento passa pelo princípio de primeiro recuperar a integridade do maciço voltando a torná-lo monolítico, uma vez que as fissuras, pelas suas magnitudes, praticamente fragmentaram o bloco, reduzindo sua rigidez global. Com o excesso de 
fissuras, há também a perda de capacidade resistente de parte das armaduras, estimando que as mesmas possam ter entrado em processo de escoamento, o que demandou ainda de se adotar solução de reforço estrutural.

Para que seja viável o correto dimensionamento das soluções de recuperação dos blocos, foi adotada uma série de hipóteses a seguir relatadas:

> As fissuras tendem a se estabilizar, se as suas principais causas se dissiparem e se as mesmas forem recuperadas (fissuras passivas);

> As armaduras de tração do modelo biela-tirante utilizado no bloco foram instaladas de forma correta na parte inferior, conforme recomendações de projeto;

$>$ O bloco foi projetado pelo modelo rígido, respeitando-se as recomendações técnicas da ABNT NBR6118 (ABNT, 2014);

- A função da recuperação é restaurar a capacidade resistente das bielas de compressão;

> A execução das estacas abaixo dos blocos foi realizada conforme orientações de projeto (prova de carga e monitoramento de recalque).

A partir das hipóteses supramencionadas, o propósito principal desta recuperação estrutural foi de restaurar a capacidade resistente da biela de compressão do bloco (papel típico de projeto atribuído ao concreto), garantindo o confinamento da massa de concreto e sua integridade contra possíveis agentes agressivos do solo, embora este não esteja em condição de saturação, e ainda acrescer capacidade resistente pelo efeito de "confinamento" provocado pela estrutura complementar, equivalente ao envolvimento do entorno do bloco com uma camada de concreto

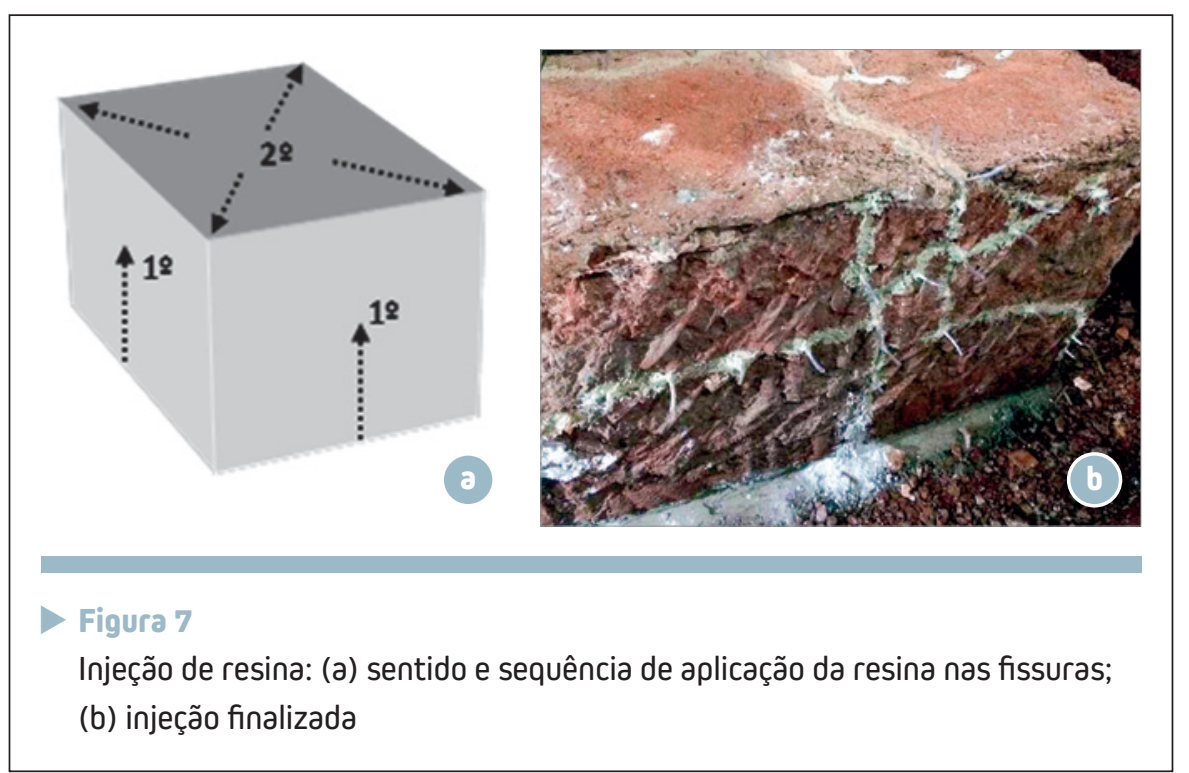

armado ao longo de suas faces laterais.

-se ajustar a sua viscosidade para tal propósito;

\section{I Recuperação da integridade do maciço}

Para que o bloco voltasse a se tornar monolítico, optou-se pela injeção de resina sintética a fim de colmatar e aglutinar as partes fragmentadas de concreto do bloco. A resina não apresenta um método de dimensionamento estrutural, mas sim a definição de especificações técnicas, tanto do produto quanto da forma de execução, que devem ser rigorosamente respeitados, uma vez que seu propósito é restaurar a integridade do maciço. Essa técnica requer uma série de cuidados no seu processo executivo, bem como devem apresentar certas características que estão melhor detalhadas em Souza e Ripper (2009). Alguns dos principais cuidados tomados com a resina foram:

- Utilização de resina de base epóxi bicomponente (isenta de solvente), capaz de ser aplicada em superfície úmida e em fissuras com espessura de 0,2mm a $8 \mathrm{~mm}$, devendo-
- Apresentar resistência à compressão final mínima de 45MPa (semeIhante à do concreto);

> Ser isenta de retração;

> Ser inerte aos agentes agressivos do solo;

> A aplicação deve ocorrer prioritariamente partindo das faces laterais do bloco no sentido da superfície superior; posteriormente, aplica-se na superfície superior do bloco, partindo da proximidade do pilar para as suas extremidades (Figura 7.a);

> Os parâmetros de pressão de injeção, dimensões e distância dos furos, (Figura 7.b) e demais cuidados especiais foram detalhados pela empresa especializada por este serviço.

\subsection{Reforço Estrutural}

Verificou-se, em função da severidade com que as fissuras se propagaram no bloco, que o processo de injeção, embora contribua para colmatar os principais vazios deixados pelas mesmas e restaurar parte da capacidade 
mecânica, ainda não seria suficiente para se garantir um nível de segurança suficiente. Desta forma, optou-se pelo reforço com o envolvimento, ao longo das laterais do bloco, com concreto armado (armadura passiva), a fim de confiná-lo quando estiver sob plena carga e garantir que os esforços do pilar sejam transferidos para as estacas de forma eficiente e com baixo nível de recalque. Embora o reforço não tenha sido dimensionado especificamente para substituir a armação preexistente no bloco, considerando ainda que a armação tenha sido solicitada mecanicamente, considera-se que o enclausuramento de concreto armado contribua para redistribuir os esforços da carga de projeto em todo o bloco, fazendo com que a armação interna continue a desempenhar sua função estrutural.

Para o dimensionamento do enclausuramento em concreto armado, necessitou-se primeiramente conhecer a ordem de grandeza dos esforços demandados nas superfícies laterais danificadas do bloco. Para tanto, foi considerado, no modelo computacional, o

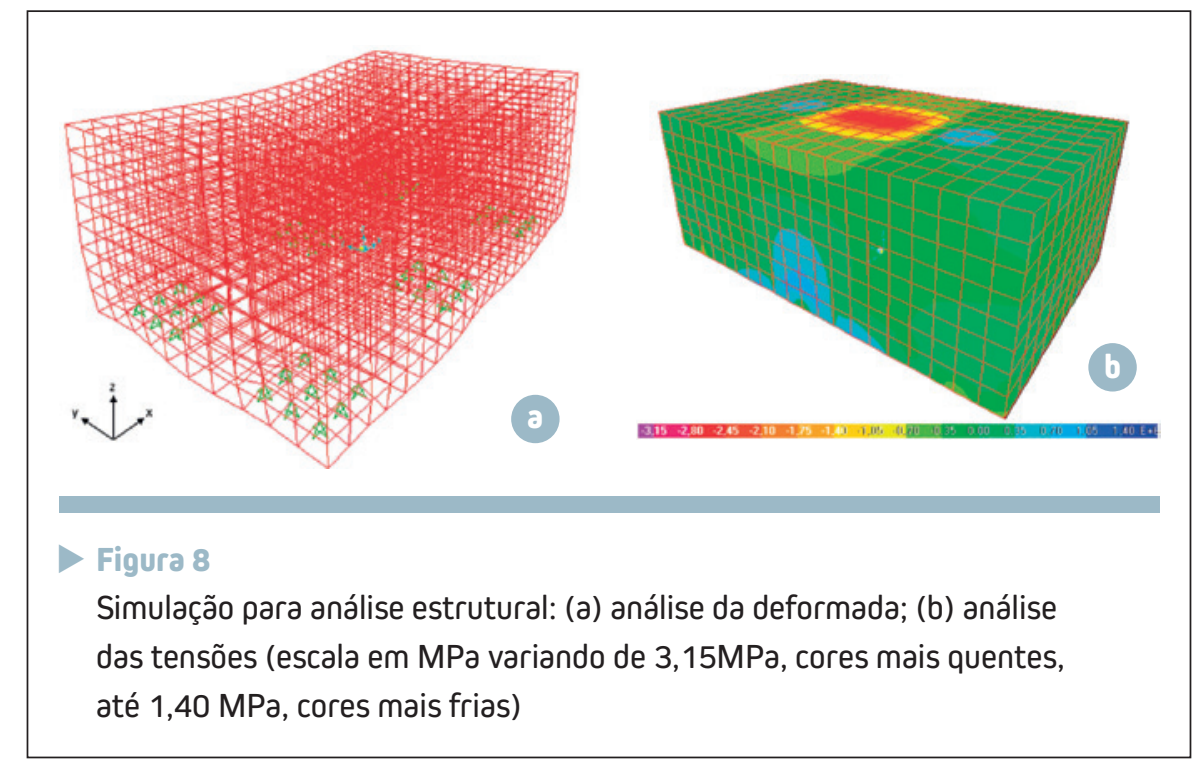

esforço de compressão do pilar na pior combinação de esforços apresentada na planta de locação dos blocos. Foi realizada a análise tensional a partir dos dados de entrada da Tabela 5, com o auxílio de software de análise estrutural SAP2000 (CSI, 2009), sem considerar efeitos de segunda ordem, na condição de deformação elástica de distribuição de tensões, e então utilizados os esforços na superfície para o dimensionamento da armadura do reforço.

\section{Tabela 5 - Dados de entrada para análise estrutural do bloco}

\begin{tabular}{|c|c|c|}
\hline \multicolumn{2}{|r|}{ Dado de entrada } & \multirow{2}{*}{ Valor } \\
\hline Tipo & Detalhamento & \\
\hline \multirow{5}{*}{$\begin{array}{l}\text { Propriedades } \\
\text { dos materiais }\end{array}$} & Resistência à compressão de cálculo (f $\left.{ }_{c d}\right)$ & $32,1 \mathrm{MPa}$ \\
\hline & Módulo de elasticidade de cálculo ( $\left.\mathrm{E}_{c d}\right)$ & $33,6 \mathrm{GPa}$ \\
\hline & Coef. de Poisson & 0,20 \\
\hline & $\begin{array}{l}\text { Tensão de escoamento do aço de cálculo } \\
\qquad\left(f_{\mathrm{yd}}\right)\end{array}$ & $434 \mathrm{MPa}$ \\
\hline & Módulo de elast. de cálculo do aço $\left(\mathrm{E}_{\mathrm{s}}\right)$ & $210 \mathrm{GPa}$ \\
\hline \multirow{2}{*}{$\begin{array}{c}\text { Esforço } \\
\text { solicitante } \\
\text { no pilar }\end{array}$} & Carregamento estático & $590 t f$ \\
\hline & Forma de aplicação & $\begin{array}{l}\text { Nós dos elementos finitos } \\
\text { do contato pilar/bloco }\end{array}$ \\
\hline \multirow{3}{*}{ Simulação } & Contato do bloco com as estacas & Engastamento rígido \\
\hline & Malha de elementos finitos & 1600 elementos finitos cúbicos \\
\hline & Tipo de análise & Elástica e linear \\
\hline
\end{tabular}

O comportamento deformacional do bloco está consistente com o modelo de cálculo preconizado pela norma ABNT NBR 6118 (ABNT, 2014) em seu item 22.7 (modelo biela-tirante tridimensional) e visualizado por meio das deformadas - Figura 8.a. Percebe-se que a região de tração no nível da interface com as estacas (região dos tirantes interligando as estacas) faz com que ocorra esforços de tração da ordem de $1 \mathrm{MPa}$ na superfície lateral do bloco (Figura 8.b). Essa distribuição de tensões internas somente é possível de ser garantida com a integridade estrutural do concreto sob compressão em seu núcleo decorrente da carga advinda do pilar.

Assumindo o fato das fissuras terem afetado a capacidade do concreto em absorver as tensões de tração na superfície do concreto, o enclausuramento do bloco foi dimensionado para que uma armação no entorno mantenha o confinamento original, apto a garantir a distribuição tensional original simulada. Vale também notar do comportamento mecânico do bloco na Figura 8 que em sua superfície superior há a ocorrência de tensões de tração que, mesmo em 
pequena magnitude em relação à capacidade resistente do concreto, podem induzir à formação e propagação das primeiras fissuras em conjunto com o efeito provocado pelas tensões de origem térmica.

Foi assumida a espessura do reforço em concreto com $f_{c k}$ de $45 \mathrm{MPa}$ de $20 \mathrm{~cm}$, para encobrir imperfeições dimensionais significativas do bloco original e envolver a armadura complementar. Nesta configuração, o nível de esforços de tração médio no entorno do bloco foi de aproximadamente $150 \mathrm{kN}$ (principalmente no $1^{\circ}$ um terço da altura do bloco), que demandou uma armação longitudinal (na direção das maiores dimensões do bloco) de $10 \mathrm{~mm}$ de diâmetro a cada $15 \mathrm{~cm}$. Já, a armadura transversal do reforço visou garantir a estabilidade dimensional deste novo concreto, distribuir os esforços de forma igualitária no reforço e ainda engastar a armação a partir de ganchos chumbados no concreto antigo. Para tanto, dimensionou-se armadura de $8 \mathrm{~mm}$ de diâmetro, com espaçamento a cada $16 \mathrm{~cm}$. Apresenta-se na Figura 9 um esquema do reforço.

As armações tiveram cobrimento de $5 \mathrm{~cm}$ em relação à face externa. Para garantir a devida junção do reforço ao bloco, considerou-se a ancoragem da armação transversal de 8mm embutida no bloco por meio de perfuração e injeção de resina.

\section{CONSIDERAÇÕES FINAIS}

O estudo de caso apresentado é um exemplo contundente de que a ausência de cuidados básicos no controle tecnológico do concreto e no processo de concretagem podem ocasionar grandes danos estruturais. $O$ que chama a atenção neste caso é o quão precoce as manifestações patológicas ocorreram, comprovando a severidade com que o problema térmico associado ao carregamento da superestrutura podem provocar de dano em um bloco de fundação. Medidas de natureza simples no planejamento e execução do concreto poderiam evitar, a um baixo custo, esses problemas, quando comparado com todos os transtornos diretos e indiretos dos danos ocasionados. Estima-se que os custos de reforço, comparados com os provenientes das ações de prevenção, se tivessem sido tomadas, encareceram a execução do referido bloco em mais de $200 \%$.

Dentre as ações mitigadoras, estima-se que as mais eficazes no combate às fissuras seriam: realizar a concretagem em duas camadas, com

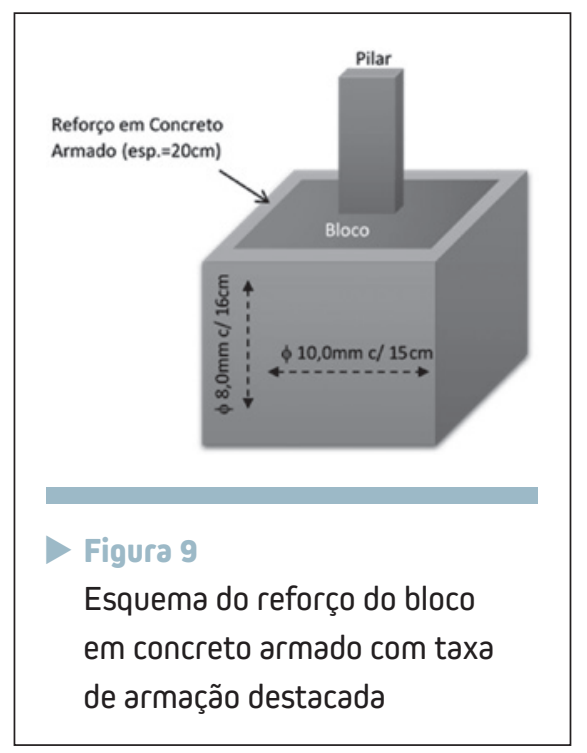

intervalo estimado de 2 dias; restringir o lançamento das camadas no período da manhã; garantir que as dimensões da escavação não ultrapassem as dimensões de projeto mais do que as permitidas pela ABNT NBR 14931 (ABNT, 2004); e conferir o posicionamento das armaduras para garantir que o cobrimento seja respeitado sem excessos e, assim, colabore no controle de eventuais fissuras superficiais. Outra alternativa para mitigar o risco térmico seria por meio da pré-refrigeração do concreto com uso de gelo ou outras técnicas de refrigeração para reduzir o pico da máxima temperatura e seus efeitos consequentes.

\section{DREFERÊNCIAS BIBLIOGRÁFICAS}

[1] ABNT. Edificações habitacionais — Desempenho Parte 1: Requisitos gerais: ABNT NBR 15.575. Rio de Janeiro, 2013.

[2] ABNT. Projeto de Estruturas de Concreto - Procedimento: ABNT NBR 6118. Rio de Janeiro, 2014.

[3] ABNT. Execução de estruturas de concreto - Procedimento: ABNT NBR 14.931, Rio de Janeiro, 2004

[4] ACl. Effect of Restraint, Volume Change, and Reinforcement on Cracking of Mass Concrete. 207.2R, USA, 1995.

[5] ACl. Control of cracking in concrete structures: 224R-90. USA, 1990.

[6] ACl. Specifications for Structural Concrete: 301M-10. USA, 2010.

[7] BOTASSI, S. S.; et. al.. Efeitos da Temperatura sobre o Concreto. Cap 23. In: Concreto: Ciência e Tecnologia. Editor: Geral Cechella Isaia. IBRACON, 2011.

[8] BOTASSI, S. S.. Fenômeno Térmico do Concreto: Fundamentos e Aplicações Práticas. $1^{a}$ Ed, Interciência - Rio de Janeiro, 2019.

[9] Computer and Structures, Inc. Strutuctural Analysis Program - SAP2000. Versão 14.0.0, Berkeley, CA - USA, 2009.

[10] EQUIPE DE FURNAS, Laboratório de Concreto, Departamento de Apoio e Controle Técnico. Concreto: Ensaios e Propriedades - Editor Walton Pacelli de Andrade São Paulo: Pini, 1997

[11] SOUZA, V. C. M.; RIPPER, T. Patologia, recuperação e reforço de estruturas de concreto. 5ª Ed., PINI, São Paulo, 2009. 